\title{
Effects of Pain and Disability on Quality of Life in Patients with Diabetic Polyneuropathy
}

\author{
Nurten Olmez ${ }^{1}$, Yildiz Degirmenci2 ${ }^{*}$, Hulusi Kececi² \\ ${ }^{1}$ Etlik Mh, Mustafa Ustundag Sk, Kecioren, Ankara, Turkey \\ ${ }^{2}$ Neurology Department, School of Medicine, Duzce University, Duzce, Turkey \\ Email: dr.nurten@gmail.com, ydegir@gmail.com, hulusikececi@hotmail.com
}

Received 31 July 2015; accepted 1 September 2015; published 4 September 2015

Copyright (C 2015 by authors and Scientific Research Publishing Inc.

This work is licensed under the Creative Commons Attribution International License (CC BY). http://creativecommons.org/licenses/by/4.0/

c) (i) Open Access

\begin{abstract}
Diabetes is a common chronic disease with a prevalence of $8.3 \%$. Diabetic neuropathy is a common neurological complication of the disease which interferes with the quality of life (QoL) of patients due to painful symptoms leading to disability. This study aims to evaluate the effects of diabetic neuropathy on disability and QoL. Sixty-two patients with clinical diabetic neuropathy were enrolled in the study. All underwent electrophysiological evaluations. Brief disability scale (BDS) and Short form-36 (SF-36) were used to evaluate disability and QoL of patients. Results revealed a negative correlation among increased pain quality assessment scale (PQAS), BDQ scores and QoL, emphasizing the interfering effect of pain on QoL of patients with diabetic neuropathy.
\end{abstract}

\section{Keywords}

Diabetic Neuropathy, Pain, Disability, Quality of Life

\section{Introduction}

Diabetes is a common chronic metabolic disease. Globally it is estimated that 387 million people suffer from diabetes. The prevalence of diabetes in adult population is $8.3 \%$ [1]. People with diabetes have an increased risk of developing a number of serious health problems including systemic and/or nervous system involvement which are known as micro and micro vascular complications. Diabetes can cause damage to the peripheral nervous system leading to neuropathy. The most common cause of peripheral neuropathy is diabetes, and $30 \%-90 \%$ of patients with diabetes have peripheral neuropathy [2].

${ }^{*}$ Corresponding author. 
Underlying pathogenic mechanisms of diabetic neuropathy can be summarized as metabolic, ischemic, immunologic, and compressive mechanisms [3] [4]. Regarding these pathogenic pathways, diabetic neuropathy has various types, in which diabetic sensory-motor polyneuropathy is the most frequent type [5] [6]. Another form of diabetic neuropathy is painful diabetic neuropathy (PDN) which encounters $16 \%-34 \%$ of patients with diabetes, and is more debilitating due to painful symptoms. Pain itself is not only a burden to patients with PDN, but also a secondary cause of disability leading sleep disturbances, mood disorders such as anxiety, and interferes with physical functioning. Thus, chronic painful symptoms in diabetes lead to various degrees of disability; it can have considerable impacts on an individual's QoL [7].

The aim of this study is to evaluate the effects of neuropathic pain on disability and QoL of patients with diabetic neuropathy.

\section{Materials and Methods}

\subsection{Study Groups}

Sixty-two diabetic patients with neuropathic complaints were enrolled the study. Patients showing other causes of neuropathy such as alcoholism, liver and kidney disease, use of drugs known to cause neuropathy, malignancy or other serious illness and patients with a family history of neuropathy were excluded from the study. All patients were informed about the consent of the study and gave their approval. The study was approved by the local ethical committee of our faculty.

\subsection{Laboratory and Electrophysiological Evaluations}

Socio-demographic features of the patients with routine blood test results including serum fasting glucose, hemoglobin A1C, vitamin B12, folic acid levels, thyroid and lipid panels, liver, kidney function tests with serum electrolytes were recorded. Medical history of the patients was also assessed. Following a detailed neurological examination, all patients underwent electrophysiological evaluation. The electro diagnostic studies were performed according to standard techniques [8]. These were performed in at least two arms and one leg. Motor nerve conduction studies included the determination of conduction velocity, amplitudes and latencies after stimulation of the median, ulnar, peroneal and tibial nerves. Sensory nerve conduction studies included the antidromic determination of conduction velocity, latencies and amplitude of the sensory nerve action potential of the median, ulnar, radial and sural nerves [8].

Polyneuropathy defined as the the amplitude of either or both of the motor and sensory action potentials was decreased or remained normal, with normal or abnormal conduction times (velocities, distal latencies, and Fwave latencies) [9].

After the confirmation of neuropathy with electrophysiological evaluations, all patients were assessed by the same neurological examiner with a face-to-face interview and fulfilled three different questionnaires including Pain Quality Assessment Scale (PQAS), BDQ, and Short form-36 (SF-36).

\subsection{Questionnaires}

Pain quality was assessed with PQAS which was validated to Turkish by Sahin and colleagues [3]. PQAS contains 20 items that assess global pain intensity and unpleasantness, two spatial aspects of pain, and 16 different pain qualities. Following the introduction, respondents are asked to rate the severity of each of 20 pain domains using 0 - 10 numerical rating scales, where $0=$ "no pain" or "not [sensation/item]" and $10=$ "the most [descriptor] pain sensation imaginable". As mentioned above, the pain domains assessed include two global domains (pain intensity and unpleasantness), two spatial domains (deep and surface), and 16 quality domains (sharp, hot, dull, coldness, sensitive, tender, itchy, shooting, numb, electrical, tingling, cramping, radiating, throbbing, aching, and heavy) [10].

Disability due to pain was assessed by BDQ. It is a self-rated questionnaire developed by Stewart and colleagues [11]. which assesses physical and social disability in the last 1 month. Turkish validation of the questionnaire was performed by Kaplan in 1995 [12]. It has 11 individual questions; each question has three answers as "never", "sometimes", "every time" corresponding to the scores of $1,2,3$, respectively. Total score of these questions makes one score of 0 - 22. A global BDQ score between " 0 - 4" yielded no disability, while score between " $5-7$ " correspond to mild disability, " $8-12$ " correspond to moderate disability, and " $\geq 13$ " to severe dis- 
ability [11] [12]. Quality of life of the patients was evaluated with SF-36. This health survey questionnaire has an eight-scale profile evaluating physical and mental health. Physical health domain includes physical functioning, role-physical, body pain, and general health. The mental health domain measures vitality, social functioning, role-emotional, and mental health. The scores range from zero, the lowest possible score, to one hundred, with 100 representing the highest level of functioning and representing best health possible [13]. Turkish validation of the questionnaire was performed by Koçyiğit et al. [14].

\subsection{Statistical Evaluations}

Data were organized in a SPSS version 18.0 (Statistical Package for Social Sciences for Windows) database. Statistical analyses were performed with Pearson chi-square, Kruskall Wallis test, Pearson and Spearman correlation tests. $\mathrm{p}$ values $<0.05$ were considered to indicate statistical significance.

\section{Results}

Sixty-two patients including 37 women (59.68\%) and 25 men (40.32\%) with the clinical diagnosis of polyneuropathy were enrolled the study [15]. Mean age of the patients were $61.84 \pm 9.45$ years. Socio-demographic features of the patients are shown in Table 1.

All patients had type-2 diabetes mellitus and all had neuropathic complaints which are summarized in Table 2.

Fourteen (22.6\%) patients had normal findings in the electrophysiological evaluations. Polyneuropathy diagnosis was confirmed with electrophysiological evaluations in 48 (77.4\%) patients. Among these, 34 patients had mix neuropathy with dominant sensory involvement and 14 patients had mix neuropathy with dominant motor involvement.

When we evaluated the symptoms of neuropathic pain due to its' time course, we found that $31(50 \%)$ patients had intermittent symptoms, 27 (43.5\%) had variable, and 4 (6.5\%) had permanent symptoms.

Mean PQAS score was $74.29 \pm 23.48$ (range $=34-142$ ). There was a statistically significant relationship between the PQAS scores and HbAlc levels, and disease duration, $\mathrm{r}=0.362 ; \mathrm{p}<0.004$, and $\mathrm{r}=0.538 ; \mathrm{p} \leq 0.001$, respectively. But there were no statistically significant relationship between PQAS and age, blood glucose levels, blood triglyceride, total cholesterol levels, $\mathrm{r}=0.208 ; \mathrm{p}=0.105, \mathrm{r}=0.198 ; \mathrm{p}=0.123, \mathrm{r}=0.132 ; \mathrm{p}=0.307$, and $\mathrm{r}=0.079 ; \mathrm{p}=0.542$, respectively.

\section{Table 1. Socio-demographic features of the patients.}

\begin{tabular}{|c|c|c|c|}
\hline & & \multicolumn{2}{|c|}{ N (\%) } \\
\hline & Illiterate & 14 & (22.6) \\
\hline & Literate & 11 & (17.7) \\
\hline & Elementary school & 28 & $(45.2)$ \\
\hline & High school & 6 & (9.7) \\
\hline & University & 3 & $(4.8)$ \\
\hline \multicolumn{4}{|l|}{ Occupation } \\
\hline & Housewife & 34 & $(54.8)$ \\
\hline & Officer & 2 & (3.2) \\
\hline & Retired & 21 & (33.9) \\
\hline & Self-employment & 4 & (6.5) \\
\hline & Farmer & 1 & (1.6) \\
\hline \multicolumn{4}{|l|}{ Marital status } \\
\hline & Married & 55 & (88.7) \\
\hline & Widow & 7 & (11.3) \\
\hline
\end{tabular}


Table 2. Neuropathic complaints of the patients.

\begin{tabular}{ccc}
\hline & N (\%) \\
\hline Shooting & $54(87.09)$ \\
Hot & $31(50.00)$ \\
Dull & $58(93.54)$ \\
Cold & $57(91.93)$ \\
Sensitive & $37(59.67)$ \\
Tender & $17(27.41)$ \\
Itchy & $13(20.96)$ \\
Shooting & $25(40.32)$ \\
Numbness & $25(40.32)$ \\
Electrical & $57(91.93)$ \\
Throbbing & $29(46.77)$ \\
Aching & $46(74.19)$ \\
Heavy & $35(56.45)$ \\
Unpleasantness & $17(27.41)$ \\
\hline
\end{tabular}

Patients gave more than one answer to the questions.

We assessed the disability due to diabetic polyneuropathy with BDQ. We found out that the disability increased as the PQAS score increased in painful diabetic neuropathy $(r=0.454 ; p=0.000)$. There was a statistically significant relationship between BDQ scores and age $(r=0.500 ; p \leq 0.001)$, and disease duration $(r=0.308$; $\mathrm{p}=0.015)$. But no statistically significant relationship was found between BDQ and blood glucose levels ( $\mathrm{r}=$ $0.043 ; \mathrm{p}=0.739)$, HbA1c levels $(\mathrm{r}=0.0215 ; \mathrm{p}=0.093)$, triglyceride levels $(\mathrm{r}=0.071 ; \mathrm{p}=0.585)$, and cholesterol levels $(\mathrm{r}=0.019 ; \mathrm{p}=0.882)$.

QoL of patients were assessed with SF-36. There were no statistically significant differences in the SF-36 domains of patients in terms of gender and education $(p>0.05)$, but there was a statistically significant relationship in all SF-36 domains of patients, in terms of age $(p<0.05)$.

When we evaluated the effects of neuropathic complaints on QoL, we found a statistically significant decrease in the SF-36 in patients with pain $(r=-0.400, p=0.001)$, sharp $(r=-0.404, p=0.001)$, hot $(r=-0.306$, $\mathrm{p}=0.015)$, dull $(\mathrm{r}=-0.289, \mathrm{p}=0.023)$, radiating pain $(\mathrm{r}=-0.325, \mathrm{p}=0.01)$, tender $(\mathrm{r}=-0.314, \mathrm{p}=0.013)$, numb $(\mathrm{r}=-0.354, \mathrm{p}=0.005)$, tingling $(\mathrm{r}=-0.258, \mathrm{p}=0.043)$, cramping $(\mathrm{r}=-0.383, \mathrm{p}=0.002)$, aching $(\mathrm{r}=$ $-0.266, p=0.036)$, surface $(r=0.652, p=000)$, and deep pain $(r=0.626, p=000)$. When we assessed the effects of these symptoms on the subscales of SF-36, we found that there was a statistically significant negative correlation between pain and physical functioning, physical role limitation, social functioning, and pain domains of SF-36. The effects of neuropathic symptoms on SF-36 domains are summarized in Table 3.

There was a statistically significant relationship between QoL of patients with diabetic neuropathy and high PQAS scores $(\mathrm{r}=-0.487 ; \mathrm{p} \leq 0.001)$, increased serum HbAlc $(\mathrm{r}=-0.476 ; \mathrm{p} \leq 0.001)$, and glucose levels $(\mathrm{r}=$ $-0.45 ; \mathrm{p} \leq 0.001)$, and positive electrophysiological findings $(\mathrm{p}<0.01)$. When we compared the SF-36 domains in patients with diabetic neuropathy according to the results of electrophysiological evaluations, we found that there was a statistically significant worsening in all domains of SF-36 in patients with abnormal electrophysiological findings (Table 4).

All domains of SF-36 were found to effected in patients whose duration of disease were above 10 years $(p<$ 0.001). Moreover, vitality and mental health domains of SF-36 were found to be effected in patients with the disease duration $>5$ years $(\mathrm{p}<0.001)$.

When we evaluated the time course of pain with domains of SF-36, we found that there was a statistically significant relationship between the permanent course and social functioning $(\mathrm{p}=0.031)$, general health $(\mathrm{p}=$ $0.006)$, mental health $(\mathrm{p}=0.006)$, and body pain $(\mathrm{p}=0.031)$ domains of SF-36. 
Table 3. The effects of neuropathic symptoms on SF-36 domains SF-36 Domains.

\begin{tabular}{|c|c|c|c|c|c|c|c|c|c|}
\hline \multicolumn{2}{|c|}{ PQAS domains } & $\mathrm{PF}$ & $\mathrm{RP}$ & $\mathrm{RE}$ & Vitality & $\begin{array}{l}\text { Mental } \\
\text { health }\end{array}$ & SF & $\begin{array}{l}\text { Body } \\
\text { Pain }\end{array}$ & $\mathrm{GH}$ \\
\hline \multirow{3}{*}{ Pain } & $\mathrm{r}$ & -0.264 & -0.317 & -0.090 & -0.151 & -0.085 & -0.340 & -0.470 & -0.010 \\
\hline & $\mathrm{p}$ & 0.038 & 0.012 & 0.484 & 0.241 & 0.510 & $\mathbf{0 . 0 0 7}$ & 0.000 & 0.936 \\
\hline & $\mathrm{N}$ & 62 & 62 & 62 & 62 & 62 & 62 & 62 & 62 \\
\hline \multirow{3}{*}{ Sharp } & $\mathrm{r}$ & -0.149 & -0.168 & -0.299 & -0.316 & -0.265 & -0.285 & -0.183 & -0.244 \\
\hline & $\mathrm{p}$ & 0.246 & 0.193 & 0.018 & 0.012 & $\mathbf{0 . 0 3 7}$ & 0.025 & 0.155 & 0.056 \\
\hline & $\mathrm{N}$ & 62 & 62 & 62 & 62 & 62 & 62 & 62 & 62 \\
\hline \multirow{3}{*}{ Hot } & $r$ & -0.151 & -0.158 & -0.153 & -0.146 & -0.265 & -0.205 & -0.310 & -0.080 \\
\hline & $\mathrm{p}$ & 0.241 & 0.221 & 0.236 & 0.256 & 0.038 & 0.110 & 0.014 & 0.535 \\
\hline & $\mathrm{N}$ & 62 & 62 & 62 & 62 & 62 & 62 & 62 & 62 \\
\hline \multirow{3}{*}{ Dull } & $r$ & -0.194 & -0.307 & -0.093 & -0.124 & -0.138 & -0.299 & -0.502 & -0.043 \\
\hline & $\mathrm{p}$ & 0.131 & 0.015 & 0.474 & 0.338 & 0.285 & 0.018 & 0.000 & 0.740 \\
\hline & $\mathrm{N}$ & 62 & 62 & 62 & 62 & 62 & 62 & 62 & 62 \\
\hline \multirow{3}{*}{ Cold } & $r$ & -0.307 & -0.298 & -0.249 & -0.110 & -0.094 & -0.365 & -0.392 & -0.122 \\
\hline & $\mathrm{p}$ & 0.015 & 0.019 & 0.051 & 0.394 & 0.468 & 0.004 & 0.002 & 0.344 \\
\hline & $\mathrm{N}$ & 62 & 62 & 62 & 62 & 62 & 62 & 62 & 62 \\
\hline \multirow{3}{*}{ Sensitive } & $r$ & -0.349 & -0.342 & -0.240 & -0.383 & -0.375 & -0.250 & -0.185 & -0.298 \\
\hline & $\mathrm{p}$ & 0.005 & 0.007 & 0.061 & 0.002 & 0.003 & 0.050 & 0.151 & 0.019 \\
\hline & $\mathrm{N}$ & 62 & 62 & 62 & 62 & 62 & 62 & 62 & 62 \\
\hline \multirow{3}{*}{ Tender } & $\mathrm{r}$ & -0.306 & -0.300 & -0.298 & -0.437 & -0.447 & -0.339 & -0.211 & -0.403 \\
\hline & $\mathrm{p}$ & 0.015 & 0.018 & 0.018 & 0.000 & 0.000 & 0.007 & 0.099 & 0.001 \\
\hline & $\mathrm{N}$ & 62 & 62 & 62 & 62 & 62 & 62 & 62 & 62 \\
\hline \multirow{3}{*}{ Itchy } & $\mathrm{r}$ & -0.195 & -0.104 & -0.191 & -0.177 & -0.236 & -0.148 & -0.107 & -0.133 \\
\hline & $\mathrm{p}$ & 0.129 & 0.420 & 0.137 & 0.169 & 0.065 & 0.252 & 0.408 & 0.303 \\
\hline & $\mathrm{N}$ & 62 & 62 & 62 & 62 & 62 & 62 & 62 & 62 \\
\hline \multirow{3}{*}{ Shooting } & $\mathrm{r}$ & 0.020 & 0.028 & -0.129 & -0.161 & -0.119 & -0.022 & 0.134 & -0.192 \\
\hline & $\mathrm{p}$ & 0.878 & 0.827 & 0.318 & 0.211 & 0.357 & 0.867 & 0.299 & 0.134 \\
\hline & $\mathrm{N}$ & 62 & 62 & 62 & 62 & 62 & 62 & 62 & 62 \\
\hline \multirow{3}{*}{ Numb } & $\mathrm{r}$ & -0.202 & -0.353 & -0.137 & -0.158 & -0.239 & -0.227 & -0.156 & -0.071 \\
\hline & $\mathrm{p}$ & 0.116 & 0.005 & 0.289 & 0.219 & 0.062 & 0.076 & 0.227 & 0.585 \\
\hline & $\mathrm{N}$ & 62 & 62 & 62 & 62 & 62 & 62 & 62 & 62 \\
\hline \multirow{3}{*}{ Electrical } & $\mathrm{r}$ & -0.088 & -0.192 & -0.270 & -0.080 & -0.180 & -0.192 & -0.064 & -0.064 \\
\hline & $\mathrm{p}$ & 0.496 & 0.135 & 0.034 & 0.536 & 0.162 & 0.136 & 0.623 & 0.621 \\
\hline & $\mathrm{N}$ & 62 & 62 & 62 & 62 & 62 & 62 & 62 & 62 \\
\hline \multirow{3}{*}{ Tingling } & $r$ & -0.300 & -0.354 & -0.127 & -0.115 & -0.181 & -0.168 & -0.228 & -0.057 \\
\hline & $\mathrm{p}$ & 0.018 & 0.005 & 0.326 & 0.373 & 0.160 & 0.191 & 0.075 & 0.657 \\
\hline & $\mathrm{N}$ & 62 & 62 & 62 & 62 & 62 & 62 & 62 & 62 \\
\hline \multirow{3}{*}{ Cramping } & $\mathrm{r}$ & -0.158 & -0.152 & -0.110 & -0.016 & -0.143 & -0.126 & -0.186 & -0.034 \\
\hline & $\mathrm{p}$ & 0.220 & 0.239 & 0.395 & 0.903 & 0.268 & 0.329 & 0.149 & 0.792 \\
\hline & $\mathrm{N}$ & 62 & 62 & 62 & 62 & 62 & 62 & 62 & 62 \\
\hline \multirow{3}{*}{ Radiating } & $\mathrm{r}$ & -0.258 & -0.216 & -0.178 & -0.246 & -0.221 & -0.210 & -0.201 & -0.161 \\
\hline & $\mathrm{p}$ & 0.043 & 0.092 & 0.167 & 0.054 & 0.084 & 0.101 & 0.116 & 0.211 \\
\hline & $\mathrm{N}$ & 62 & 62 & 62 & 62 & 62 & 62 & 62 & 62 \\
\hline \multirow{3}{*}{ Throbbing } & $\mathrm{r}$ & 0.024 & 0.049 & 0.007 & 0.022 & 0.057 & 0.004 & 0.016 & 0.062 \\
\hline & $\mathrm{p}$ & 0.851 & 0.705 & 0.958 & 0.866 & 0.661 & 0.975 & 0.904 & 0.630 \\
\hline & $\mathrm{N}$ & 62 & 62 & 62 & 62 & 62 & 62 & 62 & 62 \\
\hline \multirow{3}{*}{ Aching } & $r$ & -0.323 & -0.350 & -0.330 & -0.269 & -0.247 & -0.351 & -0.395 & -0.170 \\
\hline & $\mathrm{p}$ & 0.010 & 0.005 & 0.009 & 0.034 & 0.053 & 0.005 & 0.001 & 0.188 \\
\hline & $\mathrm{N}$ & 62 & 62 & 62 & 62 & 62 & 62 & 62 & 62 \\
\hline
\end{tabular}




\section{Continued}

\begin{tabular}{|c|c|c|c|c|c|c|c|c|c|}
\hline \multirow{3}{*}{ Heavy } & $r$ & -0.246 & -0.121 & -0.093 & -0.251 & -0.322 & -0.230 & -0.137 & -0.212 \\
\hline & $\mathrm{p}$ & 0.054 & 0.347 & 0.473 & 0.049 & 0.011 & 0.072 & 0.290 & 0.098 \\
\hline & $\mathrm{N}$ & 62 & 62 & 62 & 62 & 62 & 62 & 62 & 62 \\
\hline \multirow{3}{*}{ Unpleasant } & $\mathrm{r}$ & -0.056 & -0.140 & -0.139 & -0.117 & -0.175 & -0.118 & -0.194 & -0.024 \\
\hline & $\mathrm{p}$ & 0.665 & 0.278 & 0.282 & 0.365 & 0.172 & 0.362 & 0.130 & 0.851 \\
\hline & $\mathrm{N}$ & 62 & 62 & 62 & 62 & 62 & 62 & 62 & 62 \\
\hline \multirow{3}{*}{ Deep } & $\mathrm{r}$ & -0.197 & -0.310 & -0.223 & -0.154 & -0.209 & -0.248 & -0.400 & -0.035 \\
\hline & $\mathrm{p}$ & 0.126 & 0.014 & 0.081 & 0.231 & 0.102 & 0.052 & 0.001 & 0.786 \\
\hline & $\mathrm{N}$ & 62 & 62 & 62 & 62 & 62 & 62 & 62 & 62 \\
\hline \multirow{3}{*}{ Surface } & $\mathrm{r}$ & -0.332 & -0.301 & -0.049 & -0.226 & -0.256 & -0.315 & -0.417 & -0.170 \\
\hline & $\mathrm{p}$ & 0.008 & 0.017 & 0.704 & 0.077 & 0.045 & 0.013 & 0.001 & 0.187 \\
\hline & $\mathrm{N}$ & 62 & 62 & 62 & 62 & 62 & 62 & 62 & 62 \\
\hline
\end{tabular}

$\mathrm{PF}=$ Physical functioning, $\mathrm{RP}=$ Role physical, $\mathrm{RE}=$ Role emotional, $\mathrm{SF}=$ Social functioning, and $\mathrm{GH}=\mathrm{General}$ health.

Table 4. Evaluation of SF-36 domains according to the results of electrophysiological evaluations.

\begin{tabular}{|c|c|c|c|c|c|c|c|}
\hline & $\mathrm{EPF}^{*}$ & $\mathrm{~N}$ & Mean & Std. deviation & Minimum & Maximum & $\mathrm{P}^{* *}$ \\
\hline \multirow{2}{*}{$\mathrm{PF}$} & Abnormal & 48 & 37.5000 & 30.70103 & 5.00 & 100.00 & \multirow{2}{*}{$<0.0001$} \\
\hline & Normal & 14 & 82.1429 & 21.09633 & 25.00 & 100.00 & \\
\hline \multirow{2}{*}{$\mathrm{RP}$} & Abnormal & 48 & 22.3958 & 38.67472 & 0.00 & 100.00 & \multirow{2}{*}{$<0.0001$} \\
\hline & Normal & 14 & 80.3571 & 36.92322 & 0.00 & 100.00 & \\
\hline \multirow{2}{*}{$\mathrm{RE}$} & Abnormal & 48 & 46.5556 & 45.96459 & 0.00 & 100.00 & \multirow{2}{*}{$<0.0001$} \\
\hline & Normal & 14 & 100.0000 & 0.00000 & 100.00 & 100.00 & \\
\hline \multirow{2}{*}{ Vitality } & Abnormal & 48 & 27.1875 & 14.58308 & 5.00 & 60.00 & \multirow{2}{*}{$<0.0001$} \\
\hline & Normal & 14 & 53.9286 & 13.47056 & 30.00 & 80.00 & \\
\hline \multirow{2}{*}{ Mental health } & Abnormal & 48 & 56.9167 & 15.79097 & 28.00 & 92.00 & \multirow{2}{*}{$<0.0001$} \\
\hline & Normal & 14 & 77.4286 & 5.99634 & 64.00 & 88.00 & \\
\hline \multirow{2}{*}{ SF } & Abnormal & 48 & 46.6146 & 21.22254 & 0.00 & 100.00 & \multirow{2}{*}{$<0.0001$} \\
\hline & Normal & 14 & 73.2143 & 11.86578 & 50.00 & 100.00 & \\
\hline \multirow{2}{*}{ Pain } & Abnormal & 48 & 39.1146 & 24.79967 & 0.00 & 90.00 & \multirow{2}{*}{$<0.0001$} \\
\hline & Normal & 14 & 65.1786 & 12.10786 & 45.00 & 77.50 & \\
\hline \multirow{2}{*}{ GH } & Abnormal & 48 & 47.6042 & 19.18526 & 5.00 & 85.00 & \multirow{2}{*}{$<0.0001$} \\
\hline & Normal & 14 & 80.7143 & 10.53513 & 60.00 & 90.00 & \\
\hline
\end{tabular}

${ }^{*} \mathrm{EP}=$ electrophysiological findings, ${ }^{* *} \mathrm{p}<0.05$ indicates statistical significance, $\mathrm{PF}=$ Physical functioning, $\mathrm{RP}=\mathrm{Role}$ physical, $\mathrm{RE}=\mathrm{Role}$ emotional, $\mathrm{SF}=$ Social functioning, and $\mathrm{GH}=$ General health.

There was a negative correlation between the mean PQAS and all domains of SF-36, which was statistically significant $(\mathrm{p}<0.05)$. Similarly, a statistically significant relationship was found between the mean BDQ and all domains of SF-36 $(\mathrm{p}<0.05)$.

\section{Discussion}

PDN is one of the most common causes of disability affecting approximately $16 \%-34 \%$ of the patients with diabetes [16]. Turkish study held in 2011 reported the prevalence of diabetic neuropathy determined by clinical examinations as $40.4 \%$ and neuropatic pain $14 \%$ [17].

Since the diagnosis of PDN is mainly based on clinical features, laboratory and electrophysiological examinations can be used to confirm the diagnosis. On this aspect, we performed electrophysiological evaluations in- 
cluding nerve conduction studies to all diabetic patients suffering from neuropathic complaints using standard techniques [8]. Among 62 patients with neuropathic complaints, $22.6 \%$ of them had normal electrophysiological findings, while $77.4 \%$ had abnormal results consistent with sensorimotor neuropathy. As known from the literature, distal symmetrical sensory neuropathy is the most common form of diabetic neuropathy [5] [6]. Diabetic sensorimotor neuropathy is a small fiber neuropathy and it has a rare electrophysiological detect ability encountering $10 \%$ of the all diabetic population [18]. Since we detected abnormal electrophysiological results suggesting sensorimotor neuropathy in $77.4 \%$ of our patients, we attributed this high rate to the profile of our study group, in which all patients had neuropathic complaints and clinically confirmed diagnosis of diabetic neuropathy.

In our study, there was a significant relationship between the PQAS and $\mathrm{HbAlc}$ levels, and disease duration ( $p<0.004$, and $<0.001$, respectively). As demonstrated in our study, a previous study revealed that prolonged disease duration and poor glycemic control are the important factors with worst pain scores in PDN [19] [20].

This wide spectrum of symptoms from pain to paresthesias in PDN may lead to anxiety, mood changes, impaired physical and/or emotional functioning, and sleep problems that interfere with the daily and diurnal activities of patients causing disability and a deterioration in the quality of life of patients.

On this aspect, we aimed to evaluate the burden of PDN on the QOL of patients with diabetes by assessing the possible relationship of pain on disability and QOL.

Similar to a previous study demonstrating the role of pain leading to disability in patients with diabetic neuropathy [17], our results revealed that the disability measured with BDQ increased, as the scores of PQAS increased in PDN $(r=0,454 ; p=0,000)$, and the disability was more likely to be related with age and prolonged disease duration $(r=0.500 ; p \leq 0.001, r=0.308 ; p=0.015$, respectively).

Similar to our results revealing a statistically significant negative correlation between pain and all domains of SF-36, a previous study reported that severe peripheral neuropathy was associated with significantly lower scores across all domains physical and mental [21]. Since most of the previous studies investigating peripheral neuropathy and quality of life have reported associations with physical component scores [22]-[24]. Only a few reports including our study as well, revealed global reductions in QoL scores [21]. Furthermore, we found a significant worsening in all domains of SF-36 in patients with painful diabetic neuropathy confirmed with abnormal electrophysiological evaluation results, in particular. Suggesting our results, a previous study revealed statistically significant lower values in patients with PDN in all domains of SF-36 [25]. Some other studies demonstrate a significant alteration in physical, mental and general health components of OQL in patients with PDN [26].

When we further analyzed the effects of neuropathic symptoms which are defined in PQAS on the domains of SF-36, we found that pain as well as deep pain and surface pain, sharp, numbness, tingling, cramping, aching, tender, hot, dull, and radiating pain have negative effects on QoL, while itchy, unpleasantness, and shooting pain had no effect on SF-36 and did not deteriorate the QoL of patients. However, a previous study revealed mild to moderate deterioration in QoL of patients with diabetic polyneuropathy without any difference in the scores of physical and mental domains of SF-36 [27].

\section{Conclusion}

In conclusion, as a microvascular complication of diabetes, PDN is a challenging and distressing burden due to its chronic and painful symptoms that diminish the QoL of patients. In order not to overlook and prevent this disabling complication, it is important to encourage clinicians to better identify patients with PDN in diabetic population via questioning all complaints of patients with diabetes, and to make further investigations if needed. This broad perspective in the evaluating the patients with diabetes may give a chance to better identify and manage the diabetic neuropathy complication, and to improve the QoL of patients with diabetes.

\section{Acknowledgements}

There is no funding or support.

\section{Conflicts of Interest}

There are no conflicts of interest reported by the authors. 


\section{References}

[1] International Diabetes Federation (2013) IDF Diabetes Atlas. 6th Edition, International Diabetes Federation, Brussels. http://www.idf.org/diabetesatlas.

[2] Callaghan, B.C., Cheng, H.T., Stables, C.L., Smith, A.L. and Feldman, E.L. (2012) Diabetic Neuropathy: Clinical Manifestations and Current Treatments. The Lancet Neurology, 11, 521-534. http://dx.doi.org/10.1016/S1474-4422(12)70065-0

[3] Sinnreich, M., Taylor, B.V. and Dyck, P.J. (2005) Diabetic Neuropathies. Classification, Clinical Features, and Pathophysiological Basis. Neurologist, 11, 63-79. http://dx.doi.org/10.1097/01.nrl.0000156314.24508.ed

[4] Smith, A.G. and Singleton, J.R. (2012) Diabetic Neuropathy. CONTINUUM: Lifelong Learning in Neurology, 18, 6084. http://dx.doi.org/10.1212/01.CON.0000411568.34085.3e

[5] Deli, G., Bosnyak, E., Pusch, G., Komoly, S. and Feher, G. (2013) Diabetic Neuropathies: Diagnosis and Management. Neuroendocrinology, 98, 267-80. http://dx.doi.org/10.1159/000358728

[6] Boulton, A. (2005) Management of Diabetic Peripheral Neuropathy. Clinical Diabetes, 23, 9-15. http://dx.doi.org/10.2337/diaclin.23.1.9

[7] Galer, B., Gianas, A., and Jensen, M. (2000) Painful Diabetic Polyneuropathy: Epidemiology, Pain Description, and Quality of Life. Diabetes Research and Clinical Practice, 47, 123-128. http://dx.doi.org/10.1016/S0168-8227(99)00112-6

[8] Kimura, J. (2001) Assessment of Individual Nerves. Electrodiagnosis in Diseases of Nerve and Muscle: Principles and Practice. 3rd Edition, Oxford University Press, New York, 130-177.

[9] Preston, D.C. and Shapiro, B.E. (2005) Electromyography and Neuromuscular Disorders. In: Preston, D.C. and Shapiro, B.E., Eds., Polyneuropathy, 2nd Edition, Chapter 23, Butterworth-Heinemann, Newton, 353-390.

[10] Şahin, N., Bodur, S., Salli, A. and Ugurlu, H. (2010) Reliability and Validity of the Turkish Version the Pain Quality Assessment Scale in Patients with Carpal Tunnel Syndrome. Noble Medical, 6, 26-33.

[11] Stewart, A.L., Hays, R.D. and Ware Jr., J.E. (1988) The MOS Short-Form General Health Survey: Reliability and Validity in a Patient Population. Medical Care, 26, 724-735. http://dx.doi.org/10.1097/00005650-198807000-00007

[12] Kaplan, İ. (1995) Yarıkırsalbirsağlıkocağınabaşvuranhastalardaruhsalbozukluklarınyetiyitimiileilişkisi. Türk Psikiyatri Dergisi, 6, 169-179.

[13] Ware Jr., J.E. and Sherbourne, C.D. (1992) The MOS 36-Item Short-Form Health Survey (SF-36), I. Conceptual Framework and Item Selection. Medical Care, 30, 473-483. http://dx.doi.org/10.1097/00005650-199206000-00002

[14] Koçyiğit, H., Aydemir, Ö., Fişek, G., Ölmez, N. and Memiş, A. (1999) Kısa Form-36' nın (KF-36). Türkçeiçingüvenilirliğivegeçerliliği. Romatizmalhastalığılanbirgrup hasta ileçalışma. İlaçve Tedavi Dergisi, 12, 102106.

[15] England, J.D., Gronseth, G.S., Franklin, G., Miller, R.G., Asbury, A.K., Carter, G.T., et al. (2005) Distal Symmetric Polyneuropathy: A Definition for Clinical Research: Report of the American Academy of Neurology, the American Association of Electrodiagnostic Medicine, and the American Academy of Physical Medicine and Rehabilitation. Neurology, 64, 199-207. http://dx.doi.org/10.1212/01.WNL.0000149522.32823.EA

[16] Abbott, C.A., Malik, R.A., van Ross, E.R., Kulkarni, J. and Boulton, A.J. (2011) Prevalence and Characteristics of Painful Diabetic Neuropathy in a Large Community-Based Diabetic Population in the UK. Diabetes Care, 34, 22202224. http://dx.doi.org/10.2337/dc11-1108

[17] Erbas, T., Ertas, M., Yucel, A., Keskinaslan, A. and Senocak, M., TURNEP Study Group (2011) Prevalence of Peripheral Neuropathy and Painful Peripheral Neuropathy in Turkish Diabetic Patients. Journal of Clinical Neurophysiology, 28, 51-55. http://dx.doi.org/10.1097/WNP.0b013e3182051334

[18] Ziegler, D., Papanas, N., Vinik, A.I. and Shaw, J.E. (2014) Epidemiology of Polyneuropathy in Diabetes and Prediabetes. Handbook of Clinical Neurology, 126, 3-22. http://dx.doi.org/10.1016/B978-0-444-53480-4.00001-1

[19] Gore, M., Brandenburg, N.A., Dukes, E., Hoffman, D.L., Tai, K.S. and Stacey, B. (2005) Pain Severity in Diabetic Peripheral Neuropathy Is Associated with Patient Functioning, Symptom Levels of Anxiety and Depression, and Sleep. Journal of Pain and Symptom Management, 30, 374-385. http://dx.doi.org/10.1016/j.jpainsymman.2005.04.009

[20] Spasić, A., Radovanović, V.R., Đorđević, C.A., Stefanović, N. and Cvetković, T. (2014) Quality of Life in Type 2 Diabetic Patients. Acta Facultatis Medicae Naissensis, 31, 193-200. http://dx.doi.org/10.2478/afmnai-2014-0024

[21] Venkataraman, K., Wee, H.L., Leow, M.K., Tai, E.S., Lee, J., Lim, S.C., et al. (2013) Associations between Complications and Health-Related Quality of Life in Individuals with Diabetes. Clinical Endocrinology, 78, 865-873. http://dx.doi.org/10.1111/j.1365-2265.2012.04480.x

[22] Happich, M., John, J., Stamenitis, S., Clouth, J. and Polnau, D. (2008) The Quality of Life and Economic Burden of 
Neuropathy in Diabetic Patients in Germany in 2002-Results from the Diabetic Microvascular Complications (DIMICO) Study. Diabetes Research and Clinical Practice, 81, 223-230. http://dx.doi.org/10.1016/j.diabres.2008.03.019

[23] Benbow, S.J., Wallymahmed, M.E. and MacFarlane, I.A. (1998) Diabetic Peripheral Neuropathy and Quality of Life. QJM, 91, 733-737. http://dx.doi.org/10.1093/qjmed/91.11.733

[24] Van Acker, K., Bouhassira, D., De Bacquer, D., Matthys, K., Raemen, H., et al. (2009) Prevalence and Impact on Quality of Life of Peripheral Neuropathy with or without Neuropathic Pain in Type 1 and Type 2 Diabetic Patients Attending Hospital Outpatients Clinics. Diabetes \& Metabolism, 35, 206-213. http://dx.doi.org/10.1016/j.diabet.2008.11.004

[25] Dobrota, V.D., Hrabac, P., Skegro, D., Smiljanic, R., Dobrota, S., Prkacin, I., et al. (2014) The Impact of Neuropathic Pain and Other Comorbidities on the Quality of Life in Patients with Diabetes. Health and Quality of Life Outcomes, 12, 171. http://dx.doi.org/10.1186/s12955-014-0171-7

[26] Currie, C.J., Poole, C.D., Woehl, A., Morgan, C.L., Cawley, S., Rousculp, M.D., et al. (2006) The Health-Related Utility and Health-Related Quality of Life of Hospital-Treated Subjects with Type 1 or Type 2 Diabetes with Particular Reference to Differing Severity of Peripheral Neuropathy. Diabetologia, 49, 2272-2280. http://dx.doi.org/10.1007/s00125-006-0380-7

[27] Vukojević, Z., Pekmezović, T., Nikolić, A., Perić, S., Basta, I., Marjanović, I. and Lavrnić, D. (2014) Correlation of Clinical and Neurophysiological Findings with Health-Related Quality of Life in Patients with Diabetic Polyneuropathy. Vojnosanitetski Pregled, 71, 833-838. http://dx.doi.org/10.2298/VSP120919015V

\section{Abbreviations}

QoL: Quality of life; BDS: Brief disability scale; SF-36: Short form-36; PQAS: Pain quality assessment scale; PDN: Painful diabetic neuropathy. 